[CONTRIBUTION FROM THE LABORATORY OF BETHEL COLLEGE, RUSSEI,VILLE, $\mathrm{KY}$.

\title{
THE PHYSICAL EFFECTS OF VARIOUS SALTS AND FER- TILIZER INGREDIENTS UPON A SOIL AS MODI- FYING THE FACTORS WHICH CONTROL ITS SUPPLY OF MOISTURE.
}

\author{
BY J. L. BEESON, \\ Receited June 4,1897 .
}

I PON making a comparative study of the physical properties of the Maryland soils, Milton Whitney has shown that the texture of the soil, or size of the soil particles, controls in the main the amount of moisture that each type of soil will maintain; and, therefore, determines the kind of crops best suited to each.

For early vegetables, where quick maturity rather than yield per acre is the desideratum, a large-grained, loose soil, containing from three to five per cent. of clay, which will maintain about six to eight per cent. of moisture, is best adapted. For a crop requiring a long period of growth, and when yield is an important item, the loose-grained soil will not do, but a finegrained soil, containing a large percentage of clay, and which will maintain a high percentage of moisture, will be required. Upon this basis of the texture of the various types of soil in the state, the amounts of moisture which each will maintain, and the kinds of crops growing thereon, he has ascertained with considerable accuracy what crops are best adapted to each type of soil in the state. He has suggested that it is possible, by changing the potential on the surface of the soil grains, to pull together or push apart the clay and fine silt grains of a soil, and thus increase or decrease the size of the soil spaces, either by a rearrangement of the particles or by building up or breaking down the soil aggregates. ${ }^{1}$ If this can be done, and at reasonable cost, it is clear that it would be of inestimable value to agriculture, for a farmer could thus change the texture of his soil, so as to adapt it to the best growth of that crop orcrops which would bring the best price. If this is true, one naturally inquires what compounds will loosen the soil? What make it more compact, and in what degrees? He affirms, also, that "fertilizers have a very marked effect upon the texture of soils *** that we

2 Bull. No. 2I, Maryland Experiment Station. 
have in our common fertilizers and manures very potent means of maintaining or changing the texture of soils, and thereby changing the conditions of moisture and heat which they can maintain for a crop, and that it is through this physical effect of manures and fertilizers in controlling the supply of moisture and heat within a soil under existing climatic conditions that the chief value of fertilizers and manures lies, rather than in the relatively small amount of plant food that they add to the soil."

While this may be the case, Hilgard has pointed out the fact that it has not yet been proved, and claims that Dr. Whitney is maximizing the physical idea, and minimizing the plant-food conception of the use of fertilizers. ${ }^{2}$

Hilgard, in his researches upon the alkali soils of the arid regions and their reclamation, has shown that certain alkaline saits, and especially the neutral sodium carbonate when present in the soil even in very small quantities, so puddles the soil or breaks up the soil aggregates as to render the soil very retentive of moisture and exceedingly difficult to get into and to maintain even in tolerable tilth.

The conversion of the sodium carbonate into the sulphate by the use of gypsum, all but completely restores the soil to normal conditions, when a good crop may be grown. By this means large tracts of alkali lands have already been reclaimed. He also states that upon the edges of the alkali spots, when there is only a medium amount of alkali present, the crops are better than in lands in the same locality free from alkali, owing to the fact that the latter maintain more moisture.

These facts would, it seems to me, answer affirmatively Whitney's suggestion that it is possible so to alter the size or arrangement of the soil particles, in some cases at least, as to make the soil more retentive of moisture. But what salts effect the soil most? which ones build up and which break down the aggregates? and in what degrees? still remain to be answered. Also, do the ordinary fertilizer ingredients as added in the usual quantities in practice and which so handsomely increase the yield, affect appreciably the texture of the soil, and thus the soil's supply of moisture? These questions, it was believed, could quick-

1 Bull. No. 2r, Maryland Experiment Station, pp. I8-19.

2 Agr. Sci., 6, Nos. 7 and 12. 
est and best be answered by studying separately those factors which govern the supply of the soil's moisture in an untreated soil, and then in samples of the same soil to which various salts had been added and incorporated into the soil as in practice. Those factors which govern the storing and maintenance of a supply of soil moisture may be briefly stated as follows: (I) rate of saturation of the soil with water; (2) water-holding capacity; (3) after the soil is full of water, its conservation power $(a)$ against the percolation of the water through the soil and therefore out of capillary reach, and (b) against the evaporation from the surface; and (4) finally the power of the soil to supply water to the root stratum by capillary action. Comparatively large quantities of various salts, when added to separate samples of a given soil, might be expected to modify appreciably the above-named factors of the soil. What would be the effect if the potassium of the soil were doubled as a chloride, sulphate, nitrate, carbonate, phosphate, etc.? if the lime were doubled as a sulphate, hydroxide, carbonate, etc.? if the magnesium salts? if the various commercial forms of nitrogen and phosphoric acid were doubled? What would be the effect if any two of these ingredients were added to the soil at the same time? if any three of them were added? What would be the effect of the various kinds of commercial fertilizers upon these factors? Should any of these salts have a marked effect in the quantities used, would it affect these factors appreciably, when added in the usual quantities in practice? While no attempt has been made to answer all of these questions in the work now reported, yet they serve to show the magnitude of the field and the importance of the line of inquiry. In order to deal effectively with the work it was necessary to devise a quick and accurate method of estimating these five factors which govern the soil's supply of moisture. Out of the necessities of the case grew the apparatus described below. 
PHYSICAL EFFECTS OF VARIOUS SALTS UPON SOIL. 623

APPARATUS FOR THE ESTIMATION OF THE RATE OF ABSORPTION OF WATER BY SOILS, MAXIMUM AND MINIMUM WATER-HOLD-

ING CAPACITY OF SOILS, RATE OF PERCOLATION OF WATER THROUGH SOILS, RATE OF EVAPORATION FROM SOILS, AND RATE OF CAPILLARY RISE OF WATER IN SOIIS.

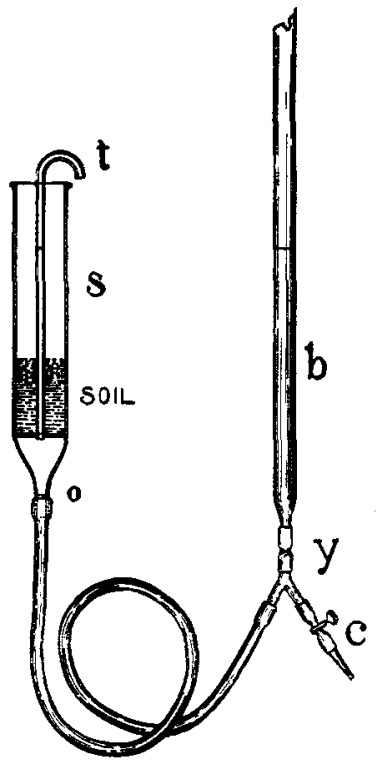

FIG. I.

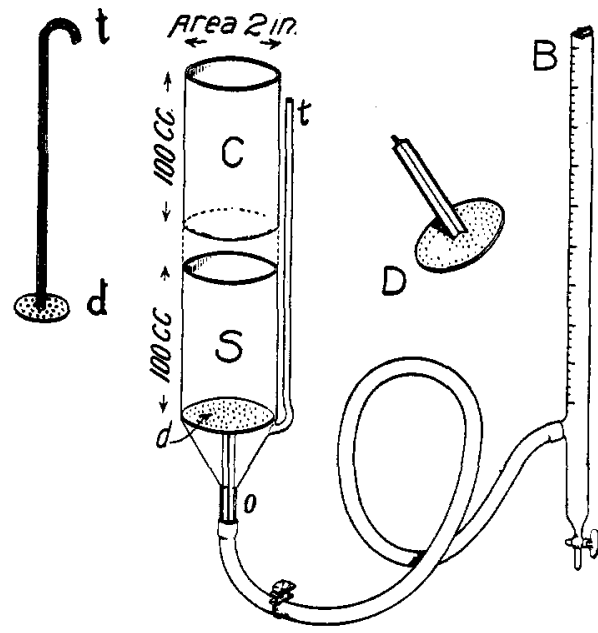

FIG. 2.

Fig. I shows the original form of the apparatus, the one with which the results embodied herein were obtained.

Fig. 2 shows the improved apparatus.

Apparatus I consists of a filter tube $S$, one and one-half inches in diameter, of such a height that it will hold roo grams of ordinary soil. It is connected by means of a stout rubber tube to a Ioo cc. side-tube burette, or by means of a $Y$-tube to an ordinary burette. A small glass tube is passed just through the center opening of a perforated copper disk, and fused in. The disk is of such a size that when a filter paper, perforated in the center, is slipped over the glass tube down upon the disk and the edges folded under, it will just fit the soil tube, $S$. The improved apparatus consists of a soil tube, $S$, of two square inches cross- 
section, and which holds exactly roo cc. Where the perforated disk, $D$, lodges there is a mark around $S$, so that the disk may be perfectly adjusted each time the instrument is used. The air tube $t$ is on the outside of the soil tube, and enters it just below the perforated disk. The cylinder $C$ is joined to $S$ by means of a ground joint, and held in place by a wide rubber band. The improved form possesses the following advantages: (I) The soil tube may be stoppered and unstoppered without settling or otherwise disturbing the soil; (2) the minimum water capacity can be readily determined with this instrument, but cannot be with the original one; (3) roocc. of the soil are weighed, and that weight taken each time when working with a given soil, and settled in the soil tube to the level. This insures an equal degree of settling in each case, a thing which is very essential in all work for comparative results. The instrument is now filled with water to the zero mark on the neck of the soil tube and on the burette. The pinch-cock at the end of the burette is of the greatest service in bringing the water to the zero mark. The zero mark may be gotten with the paper saturated or with it dry. In the latter case disks of a giren size, in which the water capacity has been determined, should be used. The instrument is now ready for use.

Rate of Capillary Rise.-Add either 100 grams or $100 \mathrm{cc}$. of the soil to the tube $S$, settle by jolting a constant number of times, and raise the burette until the water is touching the bottom of the soil, where it is kept until the stratum of capillary moisture has reached the top of the soil. The time required for this is the rate of capillary rise for this height of soil column, and is obviously a function of size and shape of the capillary spaces.

Rate of Saturation.-After the stratum of capillary moisture has reached the top, the burette is raised until its water-level is one-fourth of an inch above the top of the soil in the tube, where it is maintained. A stratum of maximum saturation, where the spaces in the soil are filled with water, slowly rises, and when it reaches the top and begins to form a surface of water on top of the soil the time is noted. The time required for the capillary ascent in this column of soil, plus that required for the maximum saturation, may be considered the rate of saturation. In 
nature the rate of saturation is variable. In low places there will be a pressure from the head of water; on the high places no pressure. So the conditions of the experiment cannot be brought to reproduce those of nature. But for all comparative results the above method is accurate.

Water-Holding Capacity.-Experience has shown that in the case of very fine-grained soils some time is required for a complete saturation, so it is well to leave the water in contact with the soil, with the instrument stoppered, for an hour after the water has made its first appearance on the top of the soil, after which the burette is lowered and allowed to stand until the burette reading is constant. Then the burette is moved so that the water stands at the zero mark on the stem of the soil tube, where the number of cc. absorbed is read, which is also the percentage. Since the specific gravity of soils varies, and since it is desired to know the quantity of water a soil will hold to a given depth, it is better to ascertain these factors in terms of volume. The small tube $t$ admits air below the disk as the burette is lowered, so that the water runs out of the soil by gravity alone, as in nature. Then it serves also to indicate the height of the water.

Rate of Percolation. - When the soil is saturated a head of one inch of water is so carefully added on top of the soil that the water is not muddied, and the time required for five cc. to run through is noted. In the improved instrument, a ground glass cylinder is attached, by means of a rubber band, to the top of the soil tube, to which the water is added.

Rate of Evaporation.-After removing the excess of water used in the preceding determination, from the top of the soil, expose the soil tube and contents to evaporation for any desired period of time. Saturate the soil again with water and read off the number of cc. absorbed, which is the amount of evaporation. Owing to the wide variation in temperature, hygrometric state, and motion of the air from hour to hour and from day to day, this method is of very little value for comparative results. But I would recommend it as a method of estimating the total evaporation during a season from a saturated soil, keeping the water in contact with the soil, and the burette and air tube stoppered. 
Minimum Water Capacity.-This important factor in the study of the physical properties of the soil may be quickly determined by the use of the improved form of apparatus, as follows: When the soil tube is full and the soil saturated, attach cylinder $C$, and fill it gently with a portion of the same soil, airdry. Allow it to absorb all the moisture it will, then remove and apply a new portion of the dry soil. Repeat until the dry soil will absorb no more moisture from the soil below. Cut off the soil even with the top of the soil tube $S$ by means of a tight thread, then raise the burette and saturate the soil with water, noting the amount absorbed. The difference between this quantity and the maximum water capacity as previously determined, is the minimum water capacity of the soil. It is thus seen that all these six estimations may be rapidly and accurately made upon the same sample of soil, one after the other, without disturbing it in the apparatus.

THE CHARACTER OF THE SOIL EXPERIMENTED WITH.

The soil, obtained from the Louisiana Experiment Station at New Orleans, is dark alluvial deposit from the Mississippi river, and is quite retentive of moisture and exceedingly fertile. Below is given both the chemical and physical analysis of the soil :

CHEMICAI, ANAIYSIS.

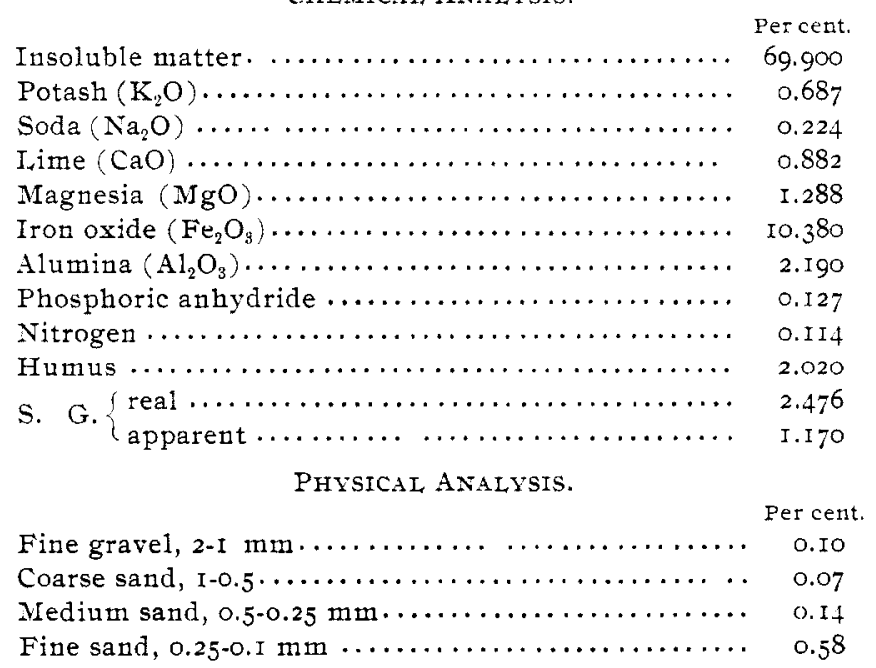




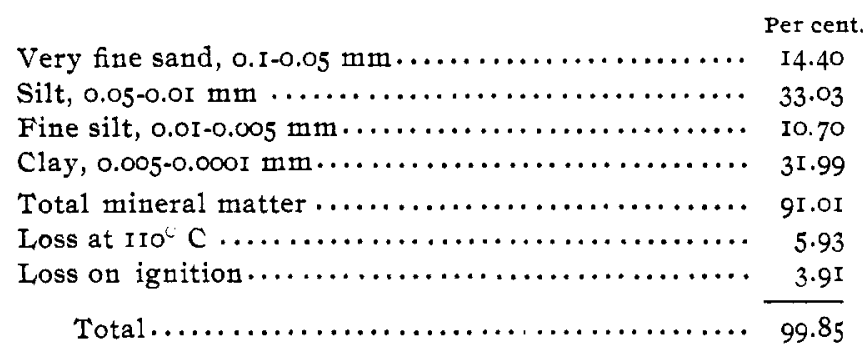

The chemical analysis was made by one of my pupils, under my supervision, following the method adopted by the Official Chemists. The physical analysis was made by Mr. Matthews, under the supervision of Milton Whitney, Washington. The soil is neither the blackest and heaviest nor the lightest type of the Mississippi bottoms, and probably represents an average rich bottom soil. Several kilos of the soil were obtained dried, ground in a coffee mill, thoroughly air-dried, and then ground so that it would pass through a sieve of forty meshes to the inch. The sample contained about nine per cent. of moisture $(8.786$ per cent.) which probably represents the minimum moisture of the soil in a drought. The soil was thoroughly mixed, placed in bottles and sealed to prevent any change in moisture content. In the experiments described in this work all results are referred to Ioo grams of this air-dried soil. The salts whose effects upon the physical properties of the soil it was proposed to study, were added directly, in a powdered form, to the soil and thoroughly incorporated with it, and the water used in the instrument was rain water, an effort being made to reproduce as near as possible the conditions in nature and in actual practice. The samples of soil, to which the various salts had been added, were kept in sealed bottles. The method of work was to study first the rate of absorption, water capacity, rate of evaporation, rate of percolation, and the capillary action of the untreated soil, then these factors in the samples, to each of which some salt had been added and incorporated. It is not claimed that the soil prepared in this way represents the exact conditions of a soil in nature, and therefore, that it will give the exact rate of saturation, percolation, etc., of a soil in the field. But it will show whether certain salts will so modify the above named factors as to change appreciably the soil's power of maintaining a 
supply of moisture. The experiments described in the following pages were made with soil apparatus No. $x$, with the soil tube one and one-half inches in diametar using fifty grams of the air-dried soil. No corrections were made for moisture, for this amount of moisture probably represents the soil's minimum moisture in nature.

\section{RATE OF SATURATION.}

A study was made of the rate of absorption of water by the soil in each successive interval of time, as follows: Fifty grams of soil were placed in the soil tube and the burette raised so as to bring the water in contact with the soil. It was allowed to remain there for one minute, then the burette was lowered for one minute and the amount absorbed read off. This process was repeated each minute until the absorption became very slow, when the water was allowed to stay in contact with the soil for a longer period. Then the burette was lowered and left down until the reading was constant. Below is given the amount of absorption for each minute of contact :

\begin{tabular}{|c|c|c|c|c|c|c|c|c|c|c|c|c|c|}
\hline Time & $\begin{array}{l}\text { Ist } \\
\text { m. } \\
\text { Per } \\
\text { cent. }\end{array}$ & $\begin{array}{c}\text { 2nd } \\
\text { m. } \\
\text { Per } \\
\text { cent. }\end{array}$ & $\begin{array}{c}3 \mathrm{rd} \\
\text { m. } \\
\text { Per } \\
\text { c'nt. }\end{array}$ & $\begin{array}{l}4^{\text {th }} \\
\text { m. } \\
\text { Per } \\
\text { c'nt. }\end{array}$ & $\begin{array}{l}\text { sth } \\
\text { m. } \\
\text { Per I } \\
\text { c't. c }\end{array}$ & $\begin{array}{l}\text { oth } \\
\text { In. } \\
\text { Per } \\
\text { c'nt. }\end{array}$ & $\begin{array}{l}\text { 7th } \\
\text { m. } \\
\text { Pet } \\
\text { cint. }\end{array}$ & $\begin{array}{l}\text { 7th } \\
\text { to } \\
\text { I2th } \\
\text { in. } \\
\text { Per } \\
\text { c't. }\end{array}$ & $\begin{array}{l}\text { I2th } \\
\text { to } \\
\text { I } 7 \text { th } \\
\text { m. } \\
\text { Pet } \\
\text { cent. }\end{array}$ & $\begin{array}{l}\text { I } 7 \text { th } \\
\text { to } \\
32 \text { thd } \\
\text { nt. } \\
\text { Per } \\
\text { cent. }\end{array}$ & $\begin{array}{l}32 \mathrm{~d} \\
\text { to } \\
47 \mathrm{th} \\
\mathrm{m} . \\
\text { Per } \\
\text { cent. }\end{array}$ & $\begin{array}{c}47 \mathrm{th} \\
\text { to } \\
77^{\mathrm{th}} \mathrm{I} \\
\mathrm{m} . \\
\text { Pet } \\
\text { cent. }\end{array}$ & $\begin{array}{l}77_{\text {th }} \\
\text { to } \\
\text { Jo7th } \\
\text { wh. } \\
\text { Per } \\
\text { c't. }\end{array}$ \\
\hline $\begin{array}{l}\text { Soil } \ldots \ldots \\
\therefore \quad+0.5 \text { pe }\end{array}$ & 26.0 & 10.4 & 6.6 & 2.0 & 0.6 & 0.4 & 0.4 & 0.52 & 0.025 & $\ldots 1$ & $\cdots$ & $\cdots$ & \\
\hline as $\mathrm{KC}$ & 16.2 & 4.0 & o & 0 & 1.0 & I.I & I. I & 0.25 & 0.37 & 0.17 & 0.18 & 0.75 & \\
\hline as $\mathrm{KNO}_{3} \ldots \ldots \ldots \ldots$ & 17.8 & 5.6 & 2.8 & 2.2 & $\therefore .4$ & I. 2 & $\mathrm{I} .2$ & 0.36 & 0.3 & 0.2 & $0, I I$ & 0.10 & \\
\hline
\end{tabular}

A stratum of capillary moisture rapidly rose to the top and was slowly followed by one of saturation. These movements, as well as the rate of absorption, were greatly decreased by the presence of the potassium salts. In the cases of both the treated and the untreated soils the rate of absorption of the water during the first minute was very large and gradually decreased until near complete saturation, when it was very slow. In the case of the untreated soil nearly half of its water capacity, measured from air dryness, was satisfied the first minute of contact. The soil column was about two inches high, and no doubt the lower stratum of one-half to one inch in thickness was practically saturated the first minute. While the water is in contact with

1 Absorbed 0.2 per cent. over night. 
the surface of a soil (the lower surface in the apparatus) the films of water around the soil particles grow thicker and thicker, filling more and more nearly the capillary spaces. This gradually decreases the surface-tension and therefore the rate of absorption.

The rate of movement of the zone of capillary moisture is very much more rapid than the zone of saturation. This is due ( $\mathrm{r}$ ) to the decrease in surface-tension above mentioned, (2) to the resistance with which the water meets in passing through the saturated zone, (3) that the saturated zone holds several times as much moisture as the capillary zone, requiring a correspondingly longer time to saturate it. The resistance due to the passage of water through a saturated stratum must be considerable when it is remembered that the percolation per square inch, under a pressure of one inch on this soil, is one and four-tenths cc. per hour, while the rate of absorption was thirteen cc. the first minute. It will be noticed that the decrease in absorption the first minute in the cases when the salts were present is not proportional to that of the entire time required, for saturation, as compared against these rates in the untreated soil. This is doubtless due to the fact that the salts had not fully dissolved during the first minute of contact. Yet this change is soon noticeable as the time of contact increases, showing that the effect of the salts is extremely rapid. The whole time required for the saturation of the samples is the better criterion by which to judge the effects of the salts upon the soil, which are given below :

\section{RATZ OF COMPLETE SATURATION.}

\begin{tabular}{|c|c|c|c|c|c|c|}
\hline & & & & & & \\
\hline & & & & & & \\
\hline & +0.5 & & & $\mathrm{~K}_{2} \mathrm{O}$ as $\mathrm{K}_{2} \mathrm{SO}_{4} \ldots \ldots \ldots \ldots \ldots$ & 60 & " \\
\hline “6 & +0.5 & ، & "6 & $\mathrm{K}_{2} \mathrm{O}$ as $\mathrm{KCl} \ldots \ldots \ldots \ldots \ldots \ldots$ & I80 & a \\
\hline “ & +0.5 & ، & “ & $\mathrm{O}_{3} \ldots \ldots \ldots \ldots \ldots$ & I8o & ‘ \\
\hline 36 & +0.5 & 6 & $"$ & $\mathrm{~K}_{3} \mathrm{PO}_{4} \ldots \ldots \ldots \ldots \ldots$ & I30 & \\
\hline “ & +0.5 & “ & " & ${ }_{3} \ldots \ldots \cdots \cdots \cdots$ & 35 & " \\
\hline 8 & +0.5 & “ & " & $\mathrm{s} \mathrm{KHCO}_{3} \ldots \ldots \ldots \ldots$ & 40 & " \\
\hline 6 & +0.5 & " & " & $\mathrm{KOH}$ & 75 & “ \\
\hline 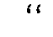 & +0.75 & & “" & $\ldots \ldots \ldots \ldots \ldots \ldots$ & 20 & " \\
\hline & $+c$ & & $"$ & $\ldots \ldots \ldots \ldots$ & 30 & 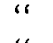 \\
\hline & + & & " & )$_{2} \ldots \ldots \cdots \cdots$ & 30 & “ \\
\hline & +0.75 & & " & $\mathrm{aO}$ as $\mathrm{CaCl}_{2} \ldots \ldots \ldots \ldots \ldots$ & 25 & " \\
\hline
\end{tabular}




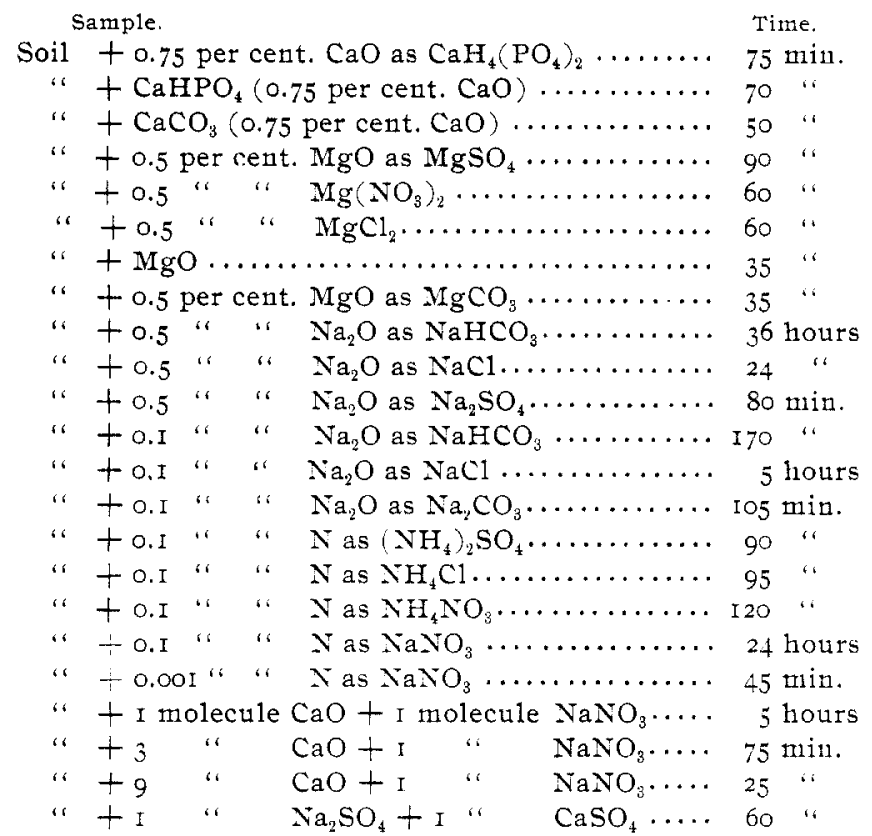

It will be observed that almost every salt added to the soil has had some effect in changing the rate of absorption of water. The most of them have decreased it; in some cases enormously. The lime salts (save the phosphates and carbonate) alone increase it, and that to too a very small extent. The alkaline salts of potassium, ammonium, and sodium have affected it most, in the order named. It is rather singular that the carbonates of potassium should have no effect, and that the carbonates of soda should have such a marked effect. While the absorption of water by the soil during short heavy showers is an important factor in the water supply, the quantities of the fertilizer ingredients added in practice are not enough to affect appreciably this factor, except sodium nitrate, when added to the amount of 0.00 I per cent. of nitrogen has reduced the rate of saturation about thirty per cent. It is further to be noticed that the addition of those salts which increase the rate of absorption, together with those which decrease it, have a neutralizing effect upon each other in the soil. Whitney has determined the surfacetension of various salt solutions and finds that certain salts 
increase and others decrease the surface-tension of water. $\mathrm{He}$ attributes largely to this variation in surface-tension, the beneficial effects of fertilizers in modifying the soil's power to maintain a supply of moisture. ${ }^{1}$ These variations in surface-tension, it seems to me, are too small to affect very appreciably the soil's supply of moisture. Then he finds that potassium chloride, ammonium sulphate, sodium nitrate, and sodium sulphate increase the surface-tension of water, and that potassium nitrate, ammonium nitrate, and potassium sulphate slightly decrease it. The former then should increase the rate of absorption of water by the soil, when present, and the latter should slightly decrease it. But the results given above show that all of these salts have decreased the rate of absorption, the size and arrangement of the soil particles remaining unchanged. It is clear then that the variations in rate of absorption due to the presence of certain salts, cannot be due to an alteration in the surface-tension. They are more likely due to the breaking-down of the aggregates of the soil into smaller ones, which would increase the ratio of the surface of the spaces to their volume, or to the rearrangement of the soil particles in such a way as to effect the same thing. If this be the cause, then these same salts ought also to decrease the rate of percolation and rate of evaporation, and increase the total capillary lift of a soil when present. Wollny has disciassed the arrangement of the soil particles after the following manner: "If we consider a soil divided up into its individual particles, each particle sensibly spherical and of the same size, there are three simple arrangements of the particles, each giving a different amount of vacant space. First, when each sphere rests upon two spheres in the space between them, as in Fig. 3- $A$, giving a spherical-sided tetrahedron between them, having a cross-section $A^{\prime}$; second, when each sphere rests upon a single sphere over its center, as in $B$, leaving a spherical-sided cubic space between, having a cross-section $B^{\prime}$; and third, an arrangement the same as the first, except having every second particle in the alternate rows omitted, as in $C$, leav-

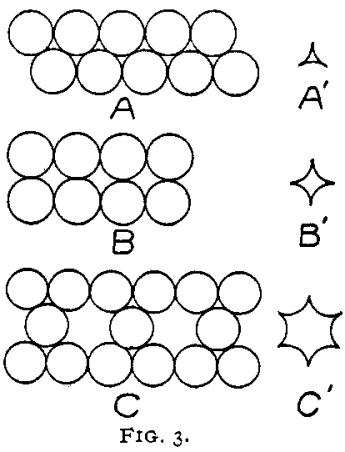

1 Wiley's Agricultural Analysis, pp. 136-137. 
ing a space with cross-section $C^{\prime}$. I would call attention to the fact ${ }^{1}$ that aggregate particles of the soil as well as simple particles, are susceptible of these three arrangements, and they are more likely to be somewhat spherical than the individual grains. The total vacant space in the first arrangement would be 30.19 per cent. of the apparent volume of the soil, in the second arrangement 47.64 per cent., and in the third 48.7 per cent. In a rearrangement of the soil particles passing from the first to the second, or to the third, there would be quite a difference in the water capacity of the soil in each. Arrangement $C$ has large and small spaces. The canals in the first arrangement are zigzag, in the other two they are straight, but with undulating sides. These facts alone would modify the rate of all kinds of capillary movements of water in the soil. If arrangements $A$ and $B$ be in combination, then the spaces will be over each other, as in arrangements $B$ and $C$, giving a total space of 38 . Io per cent. of the apparent volume of soil. In these three differently shaped canals there will be a difference in the ratio of volume of the spaces to the surface area bounding the spaces in each arrangement, and therefore different capillary values for water capacity, height of lift and capillary movements in each. While it is a fact that the soil particles are not spherical, but are more or less angular, the difference in the volume of space in these arrangements would be much greater than if the particles were spherical, and, therefore, the change in capillary values would be all the greater in passing from one form of arrangement to another. In arrangement $A$ the water capacity and capillary movements would be least and the capillary lift greatest, for a given size soil particle. This change in arrangement can be brought about in nature and practice mainly by mechanical agencies, and is by no means under perfect control. Cultivation and heavy freezes tend to move the soil particles apart and to place them in the more open arrangement, while heavy rains and stirring or tramping when wet tend to break up the soil aggregates into finer ones and to place them in the compact form of arrangement. In a soil, however, the particles are not round, which would increase the variation in passing from one form of arrangement to another; and

I Expteriment Station Record. 6, No. 9. pp. 764-5. 
PHYSICAL, EFFECTS OF VARIOUS SALTS UPON SOIL. 633

the particles are of variable sizes, and the smaller would tend to fill in the spaces between the larger. The two effects would tend to counteract each other, and to what extent would depend upon the ratio of the number of small to large particles. But in either of these three theoretical forms of arrangement, or in any other form of arrangement conceivable, the size of the soil particles, whether simple or aggregate, would determine the ratio of volume of spaces to surface area bounding them, and in a great measure all of the capillary values of the soil. Therefore, any agent which will change the size of the soil aggregates-which will build up larger ones, or break down those existing into smaller ones-will change profoundly that soil's power to hold and maintain a supply of moisture. While it is possible to control to a useful extent the texture of the upper layer of soil by judicious cultivation, so as to keep the crop mulched with a loose layer of earth, I think the results which are to follow will show that the size of the soil aggregates in the root stratum and sub-soil in the case of fine-grained soils, is also subject to control to a useful extent, and therefore the soil's power of maintaining a supply of moisture.

WATER-HOLDING CAPACITY.

The maximum water-holding capacity of any soil depends upon the total amount of space, and the size and shape of the individual spaces in the soil, and therefore upon the size and arrangement of the soil particles. In each of the three forms of arrangement of the soil particle of uniform size, there is a size of space which will just hold all its water and which represents the largest possible "maximum water-holding capacity" of that soil. If the size of the soil particle be increased or the arrangement changed so as to give larger spaces, these spaces will cease to be capillary and the water-holding power will be decreased, and if the spaces should be made smaller from any cause the water capacity of the soil would also be decreased. But in a natural soil the particles vary enormously in size. The spaces also vary in size, but very much less than the soil particles, owing to the tendency of the smaller particles to fill in the spaces between the larger ones. Yet in a natural soil, containing canals of various sizes, a certain porosity represents the 
largest water capacity of that soil, when, if its grains be pulled further apart, some of the spaces will cease to hold water, and if pulled closer together the total space is made less, and in each case the water capacity is lessened. This is true not only for the maximum water capacity, but also for the water capacity at any point along the soil column in contact with water belowfrom the stratum below where all the capillary spaces are filled with water, to the top of the column where the water capacity is minimum, where only the finest capillary canals can sustain that height of column of water. Since the soil canals are of varying sizes, and each will sustain a different height of column, it follows that there will be a gradual decrease in the water-holding power from the bottom where it is maximum, to the top where it is minimum. Whether or not this decrease is regular will depend, in a soil chemically homogeneous, upon (I) whether or not the soil column is uniformly compact. (2) whether the arrangement of the soil grains is the same at all points along the soil column, and (3) whether or not the decrease in the size of the capillary canals is regular. These conditions we should not expect to realize in nature, and should therefore expect to find an irregular decrease in water capacity upon ascending such a soil column. The larger the number of small soil particles which can fill in the spaces between the larger ones, the less the variation in the size of the capillary canals, and, therefore, the less the difference between the maximum and minimum water capacities of the soil. Thus any agent which would decrease the size of the soil aggregates would tend to increase the minimum water capacity of the soil, which would be an important factor in plant growth during a dry season. It is to be regretted that the many other duties required of me have prevented me from making a full study of the effects of various salts upon the minimum water capacity of soils, which I hope to be able to do some time in the near future. The maximum water capacity in the soil alone and in the presence of the various salts experimented with was determined, but there was so little difference between that of the soil alone (which was 54.4 per cent.) and that of the samples to which the various salts were added, and the variations were so irregular that it is deemed not worth while to give their results here. None of the salts increased the 
water capacity, and none decreased it more than six per cent. While the water capacity of the soil is an important factor in plant growth, since it represents the soil's supply of moisture, yet the variations due to the presence of the salts are too small to be of any practical value.

PERCOLATION OF WATER THROUGII SOILS.

During the absorption of rain by a soil the capillary action and gravity act together to move the water downward until the soil spaces are filled, when the surface-tension is zero and gravity acts alone to move the water downward. The water from the surface and from the spaces in the soil, which are too large to hold their water, thus tends to percolate through the soil. This movement of the water by gravity is resisted by the friction on the sides of the capillary canals of the soil, and whether due to the friction between water and water, or between water and the soil grain, or to both, the amount of resistance is proportional to the surface area hounding the spaces. It is clear then that the arrangement of the soil grains, whether simple or aggregate, according to one or more of the three possible ways, and also the size of the soil grains in any form of arrangement whatever, will affect this ratio of volume to area of bounding surface of the capillary canals. The size of the soil particles remaining the same, the arrangement in Fig. $3, A$, would give the lowest rate of percolation and $C$ the greatest. In any arrangement, the smaller the size of the soil particles or aggregate, the less the rate of percolation, and vice versa. A study was made of the percolation through the soil alone and in the presence of a few salts, as follows : Fifty grams of soil were placed in the soil tube (of one and one-half inches in diameter) saturated with water, and a head of one inch of water added on top of the soil, so gently that the water was not muddied, and the time required for five cc. to pass through was noted. The next day one inch head of water was added again and the rate of percolation noted, and so on until the rate became nearly constant, giving the results tabulated below : 


\section{PERCOLATION PER HOUR.}

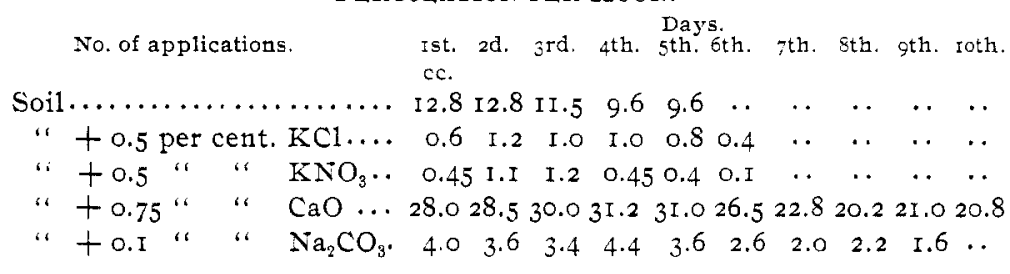

In the case of soil alone, it will be observed that the percolation gradually decreased until it reached its limit at nine and six-tenth cc. per hour. The motion of the water doubtless moved the finer particles into the larger spaces and filled them in, thus simulating a finer grained soil. It may be that the water broke up some of the aggregates into finer particles in addition. This gradual reduction of the percolation seems to be an office of the soil in preventing the waste of this most essential element of plant growth, and it seems to be a part of a general law of nature, that those things which are most essential to the growth of plants, as potash, lime, phosphoric acid, ammonia, and also water, the soil tends to conserve. By comparing the percolation through the soil alone with that of the soil when one-half per cent. of potassium chloride and potassium nitrate, and 0.75 per cent. lime were present, it will be seen that the rate of percolation was in the first two instances reduced at first to one-twenty-fifth and one-thirtieth, finally to one-twenty-fifth and one-ninety-sixth, respectively, of that through the soil alone; and in the case when lime was present, the rate was more than doubled. In the case of the potassium salts the percolation slightly increased for a time, and then decreased until it was practically nil, when the observations ceased. Indeed, it took about a week for one inch head of water to pass through the soil. The percolation in the case of the lime also increased for a time, and then decreased, becoming constant at about $20.4 \mathrm{cc}$. per hour. In the case where the potassium salts were present the soil had the appearance of being puddled, which it doubtless was, while the soil containing the lime looked granular. This fact and the preceding ones, tend to show that these changes in the percolation power of the soil, is due to a change in the size of the soil particles, and would therefore persist after the salts were removed,how long, would depend, of course, upon the subsequent treat- 
ment which the soil received. Since the surface tension during percolation is zero, the above changes in the rate of percolation cannot be due to any change in surface-tension by the salts.

Percolation after Long Standing in Contact with the Added Salts. - When the rate of percolation was determined, the water had usually been in contact with the soil for about an hour, which was sufficient time, it was believed, for most of the compounds added, to go completely into solution. However, it was thought possible that a longer time of contact might bring about a more marked change. So after the rate of percolation was determined the first time, the excess of water was removed from above the soil, that as little as possible of the salts might be washed out, and the soil allowed to stand for eighteen days, and the rate of percolation determined again each sixth day. These determinations were made with samples of soils, to each of which was added potassium carbonate, potassium chloride, potassium phosphate, calcium oxide, and calcium sulphate. The variations due to the long standing in contact with the salts were so small, the greatest being less than three per cent., that the results need not be given here. We would conclude, therefore, that the change in rate of percolation in the soil due to the presence of certain salts is effected in less than an hour's contact with the water. The decrease in the rate of percolation previously noted being probably due to the continued motion of the water through the soil, filling the larger spaces with fine grains.

Rate of Percolation per Hour Through THE SOIL AlONE AND IN ThE PRESENCE OF VARIOUS SAITS.

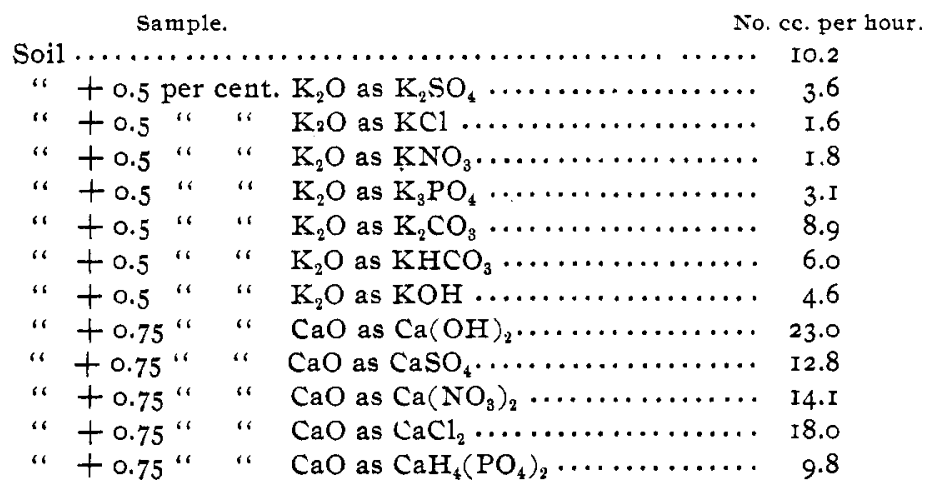


Sample.

No. cc. per hour.

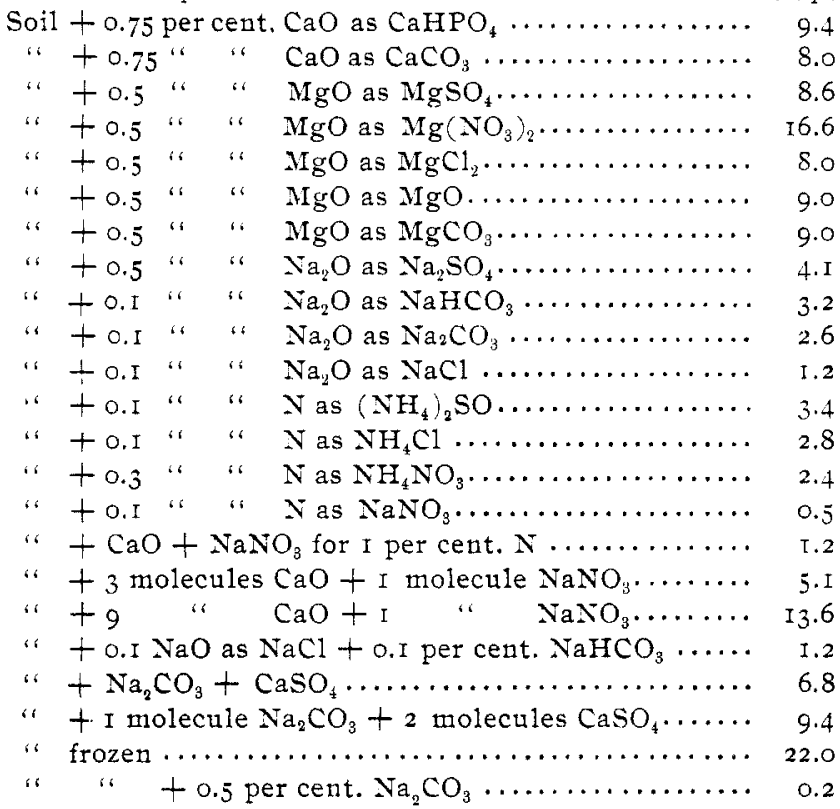

By comparing the rate of percolation through the soil to which the various salts were added, against that through the soil alone, it will be seen that all the potassium salts used have reduced the rate of percolation, the nitrate and chloride having the greatest effects; that the nitrate, chloride, sulphate, and calcium hydroxide have increased the rate of percolation, the other lime salts having little effect; that the magnesium salts have little effect, except the nitrate which has increased the percolation; that the ammonium salts used have decreased the rate of percolation much more than the potassium salts; that the sodium carbonate and chloride, and especially the nitrate, have a remarkable effect in reducing the rate of percolation. Onetenth per cent. of soda as sodium chloride has reduced the rate of percolation to one-tenth, and one-tenth per cent. of nitrogen as sodium nitrate has reduced it to one-twentieth of the rate through soil alone.

These variations are enormous, and since the greatest effects of the salts upon the percolation are not developed during the first determination, but increase as the water 
continues to pass through, it is believed that these results would show that the quantities of these salts which it is practical to add to the soil would be sufficient to make a great difference in the escape of the water of the soil by percolation, and therefore in the amount of water which a soil so treated can maintain for the growth of a crop.

The soil in which there was a great reduction in the rate of percolation, due to the presence of certain salts, in each case had the appearance of being puddled, which it undoubtedly was. Slaked lime had the greatest effect in increasing the rate of percolation, which agrees with the common experience of the farmer that lime makes the soil more open and porous. It will be observed that molecular quantities of lime added to the soil to which sodium nitrate (one-tenth per cent. nitrogen) had been added, did not restore its permeability, nor did three times the molecular quantity do so. Nine times the quantity increased the permeability to about one-third more than that of the soil alone. We therefore conclude that sodium nitrate is about seven times more effective in decreasing the rate of percolation than lime is in increasing it.

It was thought desirable to know the quantitative effect of a freeze upon the rate of percolation of a soil. After determining the rate of percolation in a sample it was allowed to freeze in the soil tube, and after thawing, the vacant space all around between the soil and the soil tube was filled in with melted paraffin. The rate of percolation was then determined and was found to be a little more than double that of the soil below freezing. After this experiment enough sodium carbonate was added to the water remaining on top of the soil to give one-half per cent. sodium oxide, and the next day the rate of percolation was determined and was found to be reduced to the extremely low figure of two-tenth cc. per hour. This was a crucial test of the puddling power of the neutral sodium carbonate. It was purposed to treat small plats of a homogeneous soil with these various salts, and after several months to cut out an oblong square from the subsoil of each and determine the rate of percolation in situ by Whitney's method,' but circumstances prevented.

1 Wiley's Agricultural Analysis, $x, 164$. 
APPLICATION OF RESULTS TO ALKALI SOILS.

As was to be expected from Hilgard's researches upon alkali soils, the neutral sodium carbonate is found to have a much greater effect in puddling the soil and therefore in reducing the rate of percolation, than the sodium sulphate. The sodium bicarbonate has a less effect than the neutral carbonate. The addition of a molecular quantity of gypsum to the soil containing the sodium carbonate, as was expected, had increased the rate of percolation of the soil containing the latter, but not to that of the untreated soil, for the sodium sulphate which is thus formed, itself reduces considerably the rate of percolation through the soil, while the calcium carbonate formed has very little effect in increasing it. When twice the molecular quantity of gypsum is added, the excess from the reaction with the sodium carbonate about neutralizes the puddling effect of the sodium sulphate, and brings the rate of percolation back to nearly that of the untreated soil. Hilgard has noticed that certain quantities of alkali present in a soil is highly advantageous to a crop in the semi-arid region by increasing the moisture in the soil. It seems to be one of the compensating forces of nature that the presence of the alkali in the soil, which is the result of a scarcity of rainfall, is the means of conserving for plant growth the little water which does fall.

I would suggest the following as a quick method of determining the quantity of ameliorant needed to relieve the excessive puddled condition of alkali salts : Establish as near as possible a standard for those factors which govern the soil's supply of moisture by determining the rate of capillary rise, rate of saturation, rate of percolation, rate of evaporation, etc., in those semi-alkali soils which are yielding the best crops, then by adding constantly increasing quantities of the gypsum to samples of soil from the alkali spots to be treated, the quantity required to bring the soil back to the standard may be determined to a close approximation. In this way the needs of the soil would be indicated without waiting for a year of experimentation with a crop.

RATE OF EVAPORATION AND RATE AND HEIGHT OF CAPILIARY IIFT.

The rate of evaporation from the soil depends upon the sur- 
face area exposed and the motion, temperature, and humidity of the air, which would be approximately the same for a given surface of any soil, exposed at the same time and under the same conditions; and, also, upon the power of the soil to supply water to the surface by capillary action. In a column of soil full of water exposed to evaporation, the cavities in the soil which are full of water will give up their contents to both the large and small capillary canals which will deliver the water to the surface to meet the evaporation and plant use. As the lowering of the level of water thus proceeds, the largest capillary canlals will cease one by one to deliver their water, and the rate of delivery, and, therefore, of evaporation, will gradually decrease, and the level will lower until the limit of the lift of the smallest capillary canal is reached, when the evaporation will be almost nil. In the case of a long column of air-dried soil placed in contact with water below, the rate of rise is also very rapid at first, for at first all of the capillary canals are lifting the water, the large ones very rapidly, and some of the water from the larger ones is moving laterally into the smaller canals. The larger canals, one by one, reach their limit of lift and cease to carry water, leaving the smaller and smaller ones to carry it as the capillary rise proceeds. Now the rate of rise in the smaller canals is very much slower, and some of the water from them is drawn out laterally to increase the moisture of the grains whose canals are too large to carry the water at that height. Both of these act together to reduce gradually the rate of rise of the visible capillary moisture, as the height of column increases. Both the height and rate of capillary lift will depend upon the ratio of the total amount of surface-tension acting upward ( $I$ ) to the weight of the water for the height of lift; (2) to the surface area of the walls of the capillary canals, for the rate of rise. Any agent which will vary the surface-tension of the soil water, or rearrange the soil grains so as to change the shape of the capillary spaces, or change the size of the soil aggregates, will alter this ratio, and therefore the height of capillary lift, rate of capillary rise, and rate of evaporation of the soil, as well as the rate of saturation. The rate of evaporation was determined by placing twenty-five grams of the sample of soil to which the various salts had been added, in flat dishes of equal size, to each 
of which enough water was added to saturate the soil, when they were weighed, set aside for evaporation to take place, and weighed each day. The dishes were shallow and the soil was about three-fourths of an inch deep. It is to be regretted that vessels of the same dimensions as the soil tubes were not at hand, for the capillary lift in these experiments is so small, and, therefore the difference in rate of ascent, that the differences in evaporation are not what they would be in deep vessels. The capillary tests were made in the usual way by filling long tubes with soil and placing them in separate vessels of water kept to a pretty constant head. The tubes used were sixty inches long and one-fourth inch bore. They were filled by attaching a small filter tube to the end of the long tube into which the soil was added, little by little, and was jolted down into the long tube by letting fall from a constant height an equal number of times. Since the soil fell into the tube at the same time it was being jolted down, the tendency to stratify, pointed out by Hilgard, was minimized. An examination showed very little stratification. These tubes were filled as nearly in the same way, and jolted as nearly the same as could be done. In order to test the uniformity of the tamping, the one containing soil alone was filled first, and after all the others were filled a duplicate was filled with soil alone. The ascent of the two was within one inch of each other. It was not possible to keep a detailed record of the rise of each; the heights were taken after twelve and sixty days. It is to be regretted that the unexpected termination of the Louisiana Sugar School, and the unwillingness of the Experiment Station connected therewith to take up the work, terminated my observations before many of the soil columns had ceased to lift their water. However, from the two records, the comparative rate of rise may be had, and in some cases the height of lift, and is given below in inches after twelve and sixty days. The percentage of evaporation is calculated upon the total amount of water which was added, in order to saturate the air-dried soil. It is thought not worth while to give the rate of evaporation from day to day, as the ones for the day selected the third day showed the maximum differences in evaporation. 
PHYSICAL EFFECTS OF VARIOUS SALTS UPON SOIL. 643

EvaPORATION AND CAPILIARY RISE.

\begin{tabular}{|c|c|c|c|c|c|c|c|}
\hline \multirow{3}{*}{\multicolumn{2}{|c|}{$\begin{array}{l}\text { Sample. } \\
\text { Soil alone }\end{array}$}} & & & & \multicolumn{3}{|c|}{$\begin{array}{l}\text { Capillary rise. } \\
\text { Evaporation. } 12 \text { days. } 60 \text { days. }\end{array}$} \\
\hline & & & & & Per cent. & Inches. & Inches. \\
\hline & & ... & ... & n.m.n.m.n. & 55.4 & 25 & 45 \\
\hline “ & +0.5 & per & ent & $\mathrm{K}_{2} \mathrm{O}$ as $\mathrm{K}_{2} \mathrm{SO}_{4} \ldots \ldots$ & 50.14 & I $7 \cdot 5$ & 37 \\
\hline “ & +0.5 & $"$ & “ & $\mathrm{K}_{2} \mathrm{O}$ as $\mathrm{KC} 1 \ldots \ldots \ldots$ & $50.2 I$ & I 5.5 & 32 \\
\hline “ & +0.5 & “ & $"$ & $\mathrm{~K}_{2} \mathrm{O}$ as $\mathrm{KNO}_{3} \ldots \ldots$ & 48.8 & 13.0 & 26.5 \\
\hline “ & +0.5 & $“$ & $"$ & $\mathrm{~K}_{2} \mathrm{O}$ as $\mathrm{K}_{3} \mathrm{PO}_{4} \ldots \ldots$ & 53.02 & 17.8 & 34 \\
\hline " & +0.5 & $\because$ & “ & $\mathrm{K}_{2} \mathrm{O}$ as $\mathrm{K}_{2} \mathrm{CO}_{3} \ldots \ldots$ & 55.33 & 18.5 & 37 \\
\hline “ & +0.5 & “ & ، & $\mathrm{K}_{2} \mathrm{O}$ as $\mathrm{KHCO}_{3} \ldots \ldots$ & 56.16 & I 7.9 & 37 \\
\hline$“$ & +0.5 & “ & “ & $\mathrm{K} . \mathrm{O}$ as $\mathrm{KOH} \ldots \ldots$. & 50.72 & 22 & 38 \\
\hline “ & +0.75 & “ & “ & $\mathrm{CaO}$ as $\mathrm{Ca}(\mathrm{OH})_{2} \cdots$ & 50.75 & 26 & $\cdots$ \\
\hline$"$ " & +0.75 & “ & "، & $\mathrm{CaO}$ as $\mathrm{CaSO}_{4} \ldots \ldots$ & 51.72 & $3 r$ & 53.5 \\
\hline$" ،$ & +0.75 & $" ،$ & “ & $\mathrm{CaO}$ as $\mathrm{Ca}\left(\mathrm{NO}_{3}\right)_{2} \ldots$ & 57.81 & $2 \mathrm{I}$ & 33 \\
\hline$"$ & +0.75 & " & " & $\mathrm{CaO}$ as $\mathrm{CaCl}_{2} \ldots \ldots \ldots$ & 50.82 & 24 & 38 \\
\hline " & +0.75 & “ & "، & $\mathrm{CaO}$ as $\mathrm{CaH}_{4}\left(\mathrm{PO}_{4}\right)_{2}$. & 59.93 & 22 & 42.5 \\
\hline$" r$ & +0.75 & “ & " & $\mathrm{CaO}$ as $\mathrm{CaHPO}_{4} \ldots \ldots$ & 52.04 & $24 \cdot 5$ & 46.5 \\
\hline$"$ & +0.75 & “ & $"$ & $\mathrm{CaO}$ as $\mathrm{CaCO}_{3} \ldots \ldots$ & 50.33 & 28.2 & $57 \cdot 5$ \\
\hline$"$ & +0.5 & ، & " & $\mathrm{MgO}$ as $\mathrm{MgSO}_{4} \ldots \ldots$ & $49.5 I$ & 21.3 & 36 \\
\hline “ & +0.5 & " & “ & $\mathrm{MgO}$ as $\mathrm{Mg}\left(\mathrm{NO}_{3}\right)_{2} \ldots$ & 50.40 & $2 \mathrm{I}$ & 39 \\
\hline " & +0.5 & " & "“ & $\mathrm{MgO}$ as $\mathrm{MgCl}_{2} \ldots \ldots$ & 54.82 & 23 & 54 \\
\hline “ & +0.5 & “ & “ & $\mathrm{MgO}$ as $\mathrm{MgO} \ldots \ldots$ & 63.75 & 29 & 47.5 \\
\hline “" & +0.5 & “ & $"$ & $\mathrm{MgO}$ as $\mathrm{MgCO}_{3} \ldots \ldots$ & . 64.42 & $3 I$ & 50 \\
\hline
\end{tabular}

It will be observed that of the salts experimented with, potassium nitrate and potassium chloride have exerted the greatest influence in retarding both the rate of evaporation and the rate of capillary rise in the soil, and that magnesium oxide and magnesium carbonate have increased these two factors most. As a rule, those compounds which affect evaporation most affect the rate of capillary rise and in the same direction. The calcium superphosphates and the potassium carbonates are exceptions to this general rule. The hygroscopic nature of some salts would have some effect in retaining moisture per se, and independent of any modification of the arrangement or of the size of the soil particles, or of the surface-tension of the soil water. However, a glance at the rates of evaporation as given above, shows no changes which are proportional to the hygroscopicity of the salts used. In the column of untreated soil the capillary rise reached its limit at fifty inches in I Io days, column of soil plus the gypsum fifty-one inches in sixty-eight days, the soil plus calcium carbonate fifty inches in seventy-two days, soil plus calcium superphosphate fifty-one inches in I05 days, 
soil plus magnesium oxide forty-seven inches in eighty days, and soil plus magnesium carbonate forty-seven inches in seventy days. The soil column containing potassium sulphate was still rising when it reached the end of the tube at sixty inches in 140 days. This is an increase of five inches in height over that in the untreated soil. It is most probable that those salts such as potassium chloride and potassium nitrate, which reduced the rate of rise more than potassium sulphate, would also have increased the height of lift more than did the potassium sulphate. It seems to be a general rule then that those salts which when added to a soil reduce the rate of rise of capillary moisture, increase the height of lift; and conversely that those salts which increase the rate of rise, decrease the height of lift. These variations in rate and height of capillary lift, and in rate of evaporation, do not correspond to the changes in the surfacetension of water caused by these salts, as was found to be true in the study of the rate of saturation and percolation. It is to be regretted that the rate of evaporation and the rate and height of capillary rise was not determined also in the soil to which the sodium and ammonium compounds were added, that the results might appear in this statement, but it was impossible to do so.

On account of the great length of time for the capillary moisture to reach its limit of rise, it is most desirable that an empirical formula be developed for calculating the height of lift from some easily determined factors. Since the maximum water capacity is the same as the quantity of water held in a soil column just above the level of the water which is in contact with it, and the minimum water capacity is about the same as the amount of water at the limit of the capillary rise, and since the rate of capillary rise, as determined in the soil apparatus described, gives the rate of rise for the height of column used, it seems that these three factors which are so quickly determined, together with the total height of lift, would furnish the necessary data for such a formula. It is my purpose to attempt to work out such a formula sometime in the near future.

GENERAL DISCUSSION OF RESLLTS.

It will be noticed, in general, that the four principal factors which govern the soil's supply of moisture-the rate of satura- 
tion, of percolation, of evaporation, and of capillary rise-when changed by the addition of a salt to the soil, all vary in the same direction, and oppositely, to the height of lift. This would indicate that these changes are due to a common cause. And since the soil assumed a puddled appearance in the presence of each of those salts which reduced these factors, and since sodium carbonate (which is one of that number) is known to puddle the soils, there can be little doubt that the decrease in the rates of percolation, etc., is due to a breaking up of the soil aggregates into smaller ones, and also that the increase in these factors is due to a building up of the soil aggregates into larger ones. And yet it is the common experience of chemists that the neutral salts cause the formation of aggregates and precipitate fine clay when held suspended in water, and that ammonia, caustic alkalies, and their carbonates and phosphates hinder such flocculation. While these facts apparently contradict my results, except ${ }^{1}$ in the case of sodium carbonate, it must be remembered that the result in the two instances are obtained under quite different circumstances. In the one case the soil aggregates have been broken up completely; only the finest particles, almost all of which are plastic colloidal clay, are present, and they, in suspension, where they are free to move together and form aggregates large enough to settle to the bottom when salt is added to the water. Indeed all of our knowledge of the building up and breaking down of soil aggregates was obtained by the study of the behavior of soils suspended in water. In the other case, the soil mass is composed mainly of aggregates which are themselves composed of many constituents besides clay, and the fine particles are not so free to move in the water of the soil as when in suspension.

\section{APPLICATION OF RESULTS TO AGRICULTURE.}

It will be noticed that of the salts experimented with, those which most frequently occur in commercial fertilizers as potassium sulphate, calcium superphosphate, ammonium sulphate, etc., except sodium nitrate, would have very little effect when added in the quantities usual in practice upon the soil's supply of moisture, so their beneficial effects upon crops must be attrib-

1 Wollny : Experiment Station Record, 6, No. 9. p. 766. 
uted mainly to the plant-food added. But the carbonates, chloride, and nitrate of soda. have a much greater effect. While the addition of these salts would decrease greatly the rate of absorption of water, and would be of consequence in a puddled soil during a short shower, yet such a soil would become saturated during a long rainy spell-certainly during the spring rains. Then the supply of water absorbed would be more perfectly conserved in such a soil from three causes acting together, (I) the water would percolate more slowly out of the drains or out of capillary reach in the puddled soil; (2) it would rise more slowly to the surface to supply evaporation or plant growth, the delivery of the water would therefore be more constant and of longer duration; and (3) the capillary reach would be increased probably several inches, giving this much greater reservoir of ground water to draw from. Add to this the fact that the full effect of the salt added is not developed inmediately (and therefore is not shown in the above analyses), and the increased puddling effect of cultivation when any of these salts are present, and it will be seen that the addition of these salts in the quantities within the reach of the farmer will be sufficient to increase considerably the soil's power to conserve its supply of moisture. Since different kinds of crops require for their highest development, according to their nature and period of growth, quite different amounts of water, a fair degree of control of the soil's power to maintain a supply of moisture, would adapt the soil to the high development of that crop (growing in that climate), which would yield the greatest financial return to the farmer. Since the rain falls at irregular periods, and there are generally times of great need of water by every crop, the ability to increase the soil's conservation power of moisture is more important than the power to decrease it; hence we have in the carbonates, chloride, and nitrate of soda, powerful agents for regulating the soil's moisture in accordance with the need of a given crop. Since water is the most essential material for plantgrowth, the farmer should fertilize with regard to the soil's need of moisture as well as regards its need of plant-food. If this were done no one can predict what the increase in yield would be. In a commercial fertilizer one material often neutralizes the moisture-maintaining effect of another. For example, in kainit 
the loosening effect of the gypsum would about neutralize the puddling effect of the potassium sulphate. Again, to add sodium nitrate to a soil which is too retentive of moisture by nature, to supply a deficiency of nitrogen, would actually do harm. But in the case of a soil which does not maintain enough moisture for a given crop, if the soil needs nitrogen also, sodium nitrate would give the best returns. But if this soil needed no nitrogen the carbonates or chloride of soda would remedy the moisture deficiency. These results explain why sodium nitrate gave no increased yield, even with sugar-cane, which requires an abundance of moisture upon the wet soils of Louisiana. At the Louisinna Experiment Station sodium nitrates in most cases actually decreased the yield. As was to be expected in the case of these soils, the heavy application of lime gave good returns. But lime is a very much less powerful loosening agent (about one-seventh) than sodium nitrate is a puddling agent. Lime and magnesia are the most powerful compounds found so far for decreasing the water-conserving power of soils. Doubtless a mixture of the two, easily obtained by burning a magnesium limestone, would be a still more effective agent.

Since it has been shown that in one and the same sample of soil the addition of one-tenth per cent. of nitrogen as sodium nitrate decreases the rate of percolation through the soil to more than one-twentieth of that through the untreated soil, and that the addition of 0.75 per cent, of lime has increased the rate of percolation to more than double, it is clear that the chemical composition, or the kinds and amounts of the soluble bodies of the soil have an enormous effect upon the moisture-maintaining power of a soil. This is at variance with Whitney's conclusion that the fineness of the soil particle (meaning the ultimate particle) and in general the percentage of clay determine the amount of moisture that a soil will maintain. ${ }^{1}$ If he had said, "the fineness of the soil particle and the soil aggregates," the statement would have been more nearly correct. For it has just been shown that in a fine-grained soil containing a large per cent. of clay, certain salts can build up the particles into aggregates or the aggregates into larger ones, thus simulating an open coarse-grained soil ; and other compounds can break down the

1 Bull. No. 2I, Nevada Experiment Statiou. 
aggregates into smaller ones or into the ultimate particles, making an extremely close and nearly impervious soil. The percentage of clay present is a very important factor in that it furnishes the materials for the formation of these aggregates, and the greater the quantity present, the greater the range of variation in texture possible, it would seem.

A NEW METHOD OF EXAMTNING SOIIS.

By means of the improved soil instrument previously described, and from the results obtained, we have a new method for the quick examination of soils. A method which, it is believed, will give positive information concerning the moisture needs of a soil and therefore concerning the kind of crop best adapted to it, and also the kind of fertilizers or of chemical compounds to which the soil will respond most favorably in accordance with the moisture needs of a particular crop to be grown on that soil.

The results thus obtained, construed with the chemical and physical analysis of the soil, it is believed, will give enough information concerning the soil's needs, so that it will not be necessary to wait a year for field experimentation to advise the farmer as to the needs of his soil.

A NEW LINE OF FIELD EXPERIMENTATION SUGGESTED.

The results embodied in this paper show that fertilizers or chemical compounds should be added to the soil with a regard to the soil's moisture needs as well as its plant-food needs, and especially with regard to the control of the soil's moisture, so as to meet the requirements of a given crop. I would suggest this as a profitable and fruitful line of field experimentation for the Experiment Stations to take up. In the plots thus treated with regard to the moisture needs of crops, the yield per acre, quality of crop, the temperature of the soil, the percentage of moisture the soil maintains, the rate of percolation in situ by Whitney's method, and the like, may all be carefully studied. This, it is believed, would extend very greatly our knowledge of practical agriculture.

All the compounds used in these experiments were chemically pure. It is my purpose, however, to try the effects of the various commercial forms of fertilizers, and of natural products singly, and in the most general combinations, upon the soil with which 
I am working. The incompleteness of this report is to be accounted for by the fact that this piece of work was done during such spare time as I could find while teaching three classes with laboratory superintendence every afternoon.

\section{THE RAPID ESTIMATION OF URIC ACID IN URINE. ${ }^{1}$}

BY E. H. BARTLEY.

Received May 31, 1897.

THE estimation of uric acid presents well recognized difficulties, and the results obtained by any of the known methods are always open to criticism on the side of accuracy. While we admit this fact, it must also be admitted that the object for which the estimations of uric acid in urine are usually undertaken, does not require extreme accuracy. For diagnostic purposes, slight errors may usually be disregarded. Another factor often regarded by both the person afficted and the physician, as of great importance, is the time and trouble and hence the expense to be incurred in making a correct diagnosis. The methods now in vogue for the estimation of uric acid are so time-consuming that only the chemist with a well-appointed laboratory can undertake them. This fact has prevented the mass of physicians from having such estimations made, and has deprived many unfortunate sick from the benefits to be derived from a scientific diagnosis of their ailments.

A very considerable number of methods have been proposed for the estimation of uric acid. One of the oldest methods depends upon the fact that the acid is almost insoluble in water acidulated with hydrochloric acid. The acid is set free by hydrochloric acid, and after forty-eight hours it is collected on a filter, dried at $100^{\circ} \mathrm{C}$., and weighed. This method has been shown to be very unreliable, as a very considerable amount of uric acid may remain in solution. Fokker, Salkowski, and Hopkins precipitate the uric acid with ammonium chloride as acid ammonium urate, filter, wash, decompose with hydrochloric acid, let stand two hours, filter, wash, dry, and weigh on the filter. Or, the precipitated ammonium urate may be titrated with potassium permanganate, or with twentieth-normal acid. It has also been proposed to treat this precipitate with Fehling's or Pavey's copper solution, both of which are reduced by uric

1 Read at the meeting of the New York Section, May 7, I897. 